\title{
Bar codes in fisheries research: development of the "ichthyometer"
}

\author{
Yvon Morizur, André Ogor and Patrick Lespagnol \\ ITREMER, Centre de Ressources halientiques, Brest, BP 70, 29280 Plouzané, France.
}

Accepted September 9, 1994.

Morizur Y., A. Ogor, P. Lespagnol. Aquat. Living Resour., 1994, 7, 295-300.

\section{INTRODUCTION}

A patent was registered in 1991 for using bar codes to make up a fish measuring board:(1). Collection of data such as the length of the captured fish and sometimes their ages are required in order to manage fishery resources. It is a time-consuming operation as this work is carried out usually throughout the year for each species.

The computerization of this phase has been the subject of much research work (Armstrong, 1976, 1981; McAllister and Planck, 1981; Newton, 1984; Rubec and Planck, 1984; Rubec, Planck and Messieh, 1985; Armstrong, Newton and Jewell, 1986; Grainger and McLoughlin, 1986; Bayley and Illyes, 1988; Armstrong et al., 1989). Electronic fish measuring boards have been developed in Scotland, Canada and Spain, but they have not spread for a number of reasons:

- poor performance of the electronic part in a marine environment;

- lack of system portability;

- no upgrading capability for incorporating the latest advances in computing;

- deficiency in the automatic collection of fish measurement-related data such as date, location, ship, gear, mesh size, species, category, etc.;

- sampling management for ageing was ignored; therefore, each sample had to be identified manually for size, category, species, ship, gear, ship, location and date.

(1) Patent $n^{\circ}$ FR 9110113.
More recently the firm Limnoterra has modified the fish measuring board initially described by Rubec and Planck (1984) to include an electronic keypad for storing alphanumeric data over the lengths usually collected. This system is described in Chaput et al. (1992).

Going beyond these developments, Ifremer designed a more efficient and new open-ended fish measuring system -the ichthyometer- which features higher flexibility by using the bar code principle (Morizur et al., 1991). This patented (1) new system was presented to the international scientific community during the 1991 ICES statutory meeting at La Rochelle in order to improve the system for a more general use. The result of this consultation was presented to scientific users following the year (Morizur et al., 1992).

\section{SYSTEM DESCRIPTION}

This fish measuring system has been designed to operate as a sensor; the add-on electronic-computer part (data logger), which is commercially available, is then separated from the board. The assembly makes a high-performance and open-ended system which can be upgraded at any time to take the latest advances in computing into account. The system no longer requires hand-writing and, which is very convenient, is suitable for any in-situ work. Data can then be collected automatically.

The Ichthyometer is a board with bar codes read by a waterproof sensor pencil which interfaces with a pocket computer. There is no need for this computer to be directly in contact with the environment.

\section{Board}

The board must be both strong and light and is therefore made in aluminium with a duralinox profiled 
structure. Its lower part is fitted with two nonskid strips. It is $20 \mathrm{~cm}$ wide, and in its standard version, $0.75 \mathrm{~cm}$ long. A $0.75 \mathrm{~cm}$ extension is also available.

Silk-screen printing has been used for printing a number of bar code blocks with their plain meanings, and a millimetre ruler (fig. 1).

\section{Bar codes}

There are three bar code rows arranged along the loongitudinal axis of the board.

- The "Measurements" pad is made up of bar codes which are positioned according to an origin $\mathrm{O}$ on the board. This origin is the headstop for wedging the fish to be measured. The principle is based on a combination of the position and code. The first 50 centimetres are composed of bar codes for measurements to within $0.5 \mathrm{~cm}$, and the remaining centimetres provide measurements to within $1 \mathrm{~cm}$.

- An alphanumeric pad with the decimal point and a "space" key.

- A "Main Functions" pad comprising various codes for editing in or out by using the INSERT and DELETE keys or for defining descriptors such as LOCATION, SHIP, GEAR, SPECIES, CATEGORY, WEIGHT, SIZE, SEX, BOX and COMMENTS. Generally the alphanumeric pad must be used for these descriptors. A "FUNCTION" key is also provided. When activated together with a key from the alphanumeric pad, it gives an increased number of main functions.

\section{Millimetre ruler}

The millimetre ruler makes it possible to carry out measurements with one's own eyes. As required, it can also be used for conventional millimetre reading. Such measurements can be immediately keyed in using the alphanumeric pad.

\section{Sensor pencil}

The sensor pencil is a commercially available, waterproof sensor pencil interfacing between the board and the pocket computer.

\section{Data logger}

It is a programmable, pocket computer of the PSION's Organiser II type (fig. 2). It is used for managing the date and time, programming the beeps, and offers high storage capacity, in particular by means of removable datapacks. Data and software can be easily transferred to a PC or a Macintosh. An earphone may be connected so that the operator can hear the beeps in a noisy environment. For that purpose, minor modifications have been made to the commercially available equipment.

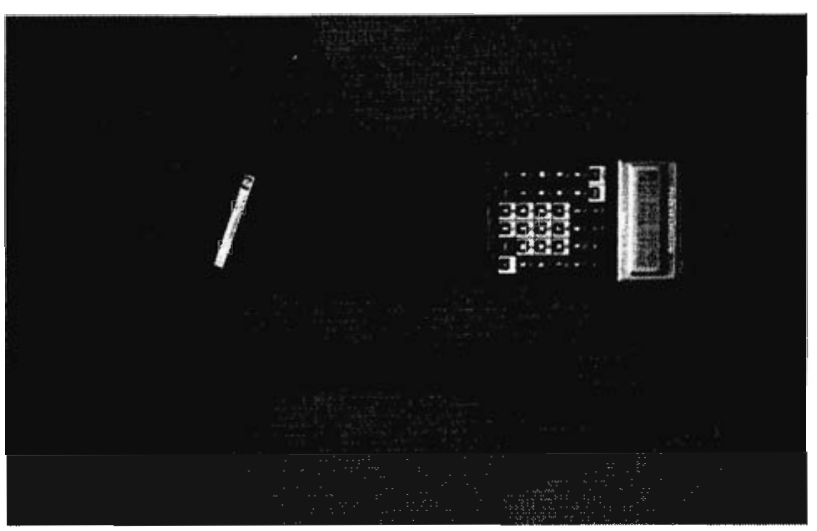

Figure 2. - The data collecting system: the Organiser II (size: $142 \times 78 \times 29 \mathrm{~mm}$; weight $250 \mathrm{~g}$ ) and the waterproof sensor pencil.

\section{Using the Ichthyometer}

A beep informs of each code acquisition. Code acquisition is made in any reading direction. All data to be collected during a sampling operation can be entered. The Ichthyometer is a highly open-ended system. The only limits are those imposed by the

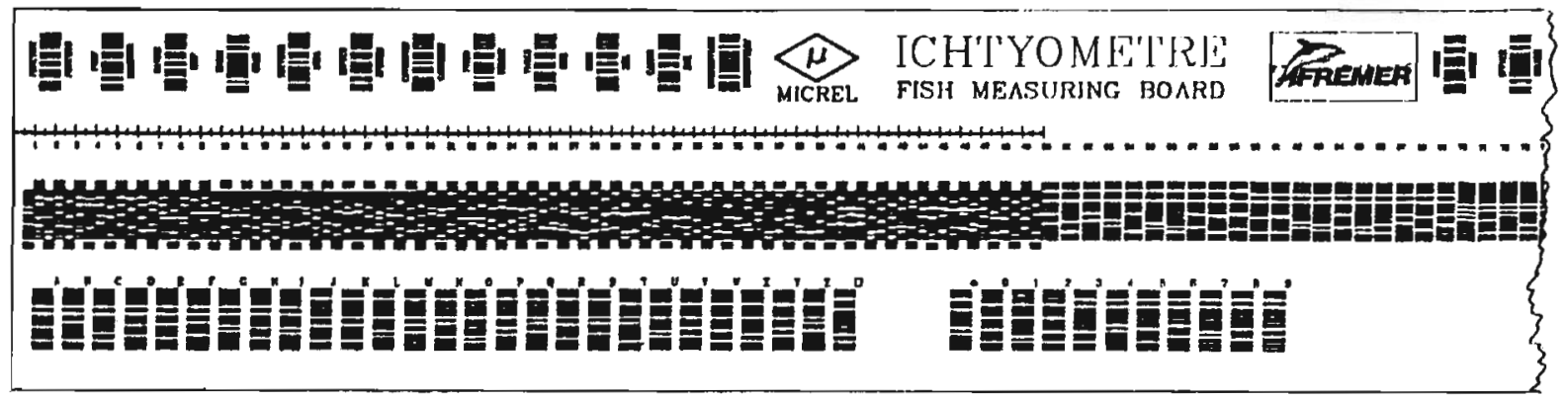

Figure 1. - The ichthyometer combines a ruler and 3 rows of bar codes: function keys (higher part), a length pad, and an alphanumeric pad (lower part). 
PC-based data processing software and data entry software.

As a general rule, the descriptor codes must be entered before their parameters. The end of the information is marked by entering another descriptor code. The parameters are keyed in from the alphanumeric pad. At first, the descriptor code entry order does not matter, provided that it is compatible with the processing software, which requires a level hierarchy (descriptor codes).

The descriptors (field names) which have been assigned to the codes can be changed, merely by modifying their names in a PC-stored match file. it is also possible to multiply their number, e.g. by means of a "function + alphabetic character" sequence, provided that it is in the match file which is used by the transcoding feature.

Measurements at the higher class limit are more easily carried out than measurements at the lower class limit. Indeed, they can be carried out with the fish wedged, while the lower limit requires the fish tail to be moved before reading if the bar code is covered too much. If the operator prefers to record the higher limits, a later correction can be made by the software for measurements rounded down to the nearest unit.

\section{TECHNICAL PROBLEMS}

Various technical problems have been examined when developing the system:

\section{Choice of a bar code}

The bar code type has been chosen to meet the following requirements:

- fewest possible number of bars for easy reading;

- capability to represent several hundred codes;

- having a check character for reading reliability;

- possibility for reading in both directions.

\section{Code size}

The $0.5 \mathrm{~cm}$ encoding implies a corresponding code width. Considering this requirement, the ideal length had to be determined. This length had to be both the shortest possible to facilitate reading and the highest possible to be insensitive to dirt or removed fish scales.

\section{Arrangement of length codes}

The codes have been arranged so that enough space can be left at the beginning and end of codes. Such space is necessary to initiate the sensor pencil movement so that its displacement speed remains the same when moving from one code to another during a reading operation. The $0.5 \mathrm{~cm}$ wide codes have been arranged in staggered rows so that they can be more easily identified. Note that whenever the pencil is misplaced on another code, reading will be disabled.

\section{Bar code holder}

\section{Choice of a material}

We decided to use a transparent polycarbonate sheet and silk-screen printing on its lower part. The thickness selected for the sheet results from a compromise making it possible to protect the codes against shocks and reduce reading difficulties due to a tarnished surface. The polycarbonate sheet is stuck on a rigid support which is in turn stuck to the board.

\section{Material ageing}

The service life of the self-adhesive sheet depends on the fish species handled and on the operator, as an uninitiated operator tends to press the pencil, which may cause scratches on the polycarbonate sheet. To incise the fish and collect the otoliths, the stop must be first pushed down to avoid damaging the self-adhesive film. When transporting the ruler, it is recommended to use a bag in order to protect the printed film.

However, a sheet which is badly scratched can be unstuck and changed, with no need to replace the whole board.

\section{Problem of fish scales}

When using the board, trouble may be caused by scales which get stuck on the printed film. A scraper attached to the end of the pencil was tested. The trials showed that it is easier to hand clean from time to time.

\section{PERFORMANCE EVALUATION}

The system is for sampling programmes at sea on small merchant ships which can take aboard only a single observer. The fish measuring board is used especially within the scope of surveys on the unwanted catches to be thrown back. Several thousand measurements have been carried out up to now.

A speed test was conducted during a sampling plan at the auction place. The handler, who was not used to this new system, sampled 4 boxes, whereas a couple (measurer + secretary) sampled 7 boxes. Considering the time for entering the data, a task to be done in the second case, and given that the handler was not yet familiar with reading bar codes, the system gives interesting performance as a minimum of 1 timeperson unit is saved, whereas the old system required 3 time-person units.

A reliability test was carried out. Various lots of fish have been measured using the conventional method and the bar code Ichthyometer. Some lots have been selected from sizes less than $50 \mathrm{~cm}$, others from sizes greater than $50 \mathrm{~cm}$, and the next from sizes around $50 \mathrm{~cm}(50 \mathrm{~cm}$ is the size for which the measurement accuracy changes from $0.5 \mathrm{~cm}$ to $1 \mathrm{~cm}$ for the present version of the system). 
Various size frequency histograms have been drawn for each lot (fig. 3):

- raw bar codes (rounded up to the nearest $0.5 \mathrm{~cm}$ or $1.0 \mathrm{~cm}$ );

- bar codes then measurement correction (rounded down);

- bar codes then correction then grouping by $1-\mathrm{cm}$ class for a comparison using the conventional method;

- conventional method (1-cm class; the measurements are rounded down to the nearest $\mathrm{cm}$ ).

The results do not show significant differences (the Kolmogorov-Smirnov tests are not significant at a 0.05 level). The minor differences may be due in equal measure to the conventional ruler or the ichthyometer. In the latter case, where the measurements are supposed to be rounded down to the nearest $\mathrm{cm}$, some values have been rounded up to the nearest $\mathrm{cm}$, the only visible value (see the samples of Solea lascaris and Scophthalmus rhombus). On the other hand, with the Ichthyometer, one cannot have measurements rounded down to the nearest half $\mathrm{cm}$, but it becomes possible to have some measurements rounded down to the nearest $\mathrm{cm}$. Indeed the code width for the $1 \mathrm{~cm}$ step lengths (lengths above $50 \mathrm{~cm}$ concerning the standard version) is much greater than the width of the sensor pencil. This enables a sensor pencil to be used, even if the fish tail overlaps onto the code, and therefore gives a measurement rounded down to the nearest centimetre.

\section{SYSTEM CAPABILITIES}

This system makes it possible to collect all data and adapt to any work situation. The only system restrictions are imposed by the software in use. Even the following information, for instance, can be entered: Comments, Measurements in $\mathrm{mm}$, Weights of lots, Individual weights, Series of data per fish (length 1, length $2, \ldots$,individual weight, ..., sex,.. ).

Organiser II stores up to about 1500 codes into a 32-Kbyte internal RAM. Its storage capacities can be significantly increased by adding RAM extension cartridges. They are available in different types (datapacks, flashdatapacks, rampacks) and in various capacities of up to 256 Kbytes. They are fitted with their own power supplies and can be sent by mail. Organiser II has a standard port to communicate directly with a host computer (RS-232 port). It can also transmit its data over the telephone network via a modem.

With its programming capacities (memories, beeps), the data logger can manage the samping plan (number of fishes per species-category to be measured, number of boxes to be measured, indication whether a sample is to be made for ageing, by managing the sampling allocation by size).

Any sampled collection may be personalized either by printing out a ticket from a mini-printer which is connected to the pocket computer, or betty by reading a "bar code label" which contains an index number. This number will be associated with the fish size in the data file which besides, contains all the required data (date, location, ship, fishing area, gear, species, category, sex, etc.). Writing data on a bar code label by means of the sensor pencil (this label can then be printed onto the sampling bag)) gives the advantage of being faster than printing a ticket, and will save time later at the laboratory during the analysis of the samples collected.

This system allows for a standardization of the data files as the measurements, which cannot be automatically collected, can nevertheless be carried out according to the conventional method, and immediately entered using a bar code tablet.

Internationalizing the language in the data files from the Ichthyometer is easily carried out. For that purpose, you merely have to modify two files which are used for later data transcoding at the laboratory.

Such a data collection principle can be implemented for fitting out ocean survey vessels. One can considerer that silk-screen printing may be added to sort or work tables for real-time data entry.

\section{ASSOCIATED SOFTWARE}

The data processing sequence is shown in figure 4 . In the present state, six software products, among them two programs developed by PSION, are to be associated with this application:

On the data logger: ICHTYO-COMMS

On the computer: CL-TRANSCOD-VALID-INSERE

ICHTYO is the OPL-written data entry software. Installed on Organiser II, the data logger, makes possible to:

- enter environmental parameters associated with any fish group to be measured (system date, operator code, location, ship, fishing area, gear, species, category);

- enter different accuracy lengths $(1 \mathrm{~cm}, 0.5 \mathrm{~cm}$, $1 \mathrm{~mm}$ );

- enter weights;

- enter data arranged into series for each fish (length 1 , length $2, \ldots$, sex..., individual weight, etc.);

- manage the samples according to a simplified plan (sampling rate, number of fishes to be measured, sub-sampling rate for collection of otoliths...);

print environmental parameters onto a ticket for each sampling;

- store bar codes (about 1500 bar codes in internal RAM);

- manage data files (retrieval, deletion);

- display all environmental parameters as required.

COMMS is the transfer software which has been developed by PSION and operates on the desktop computer. 


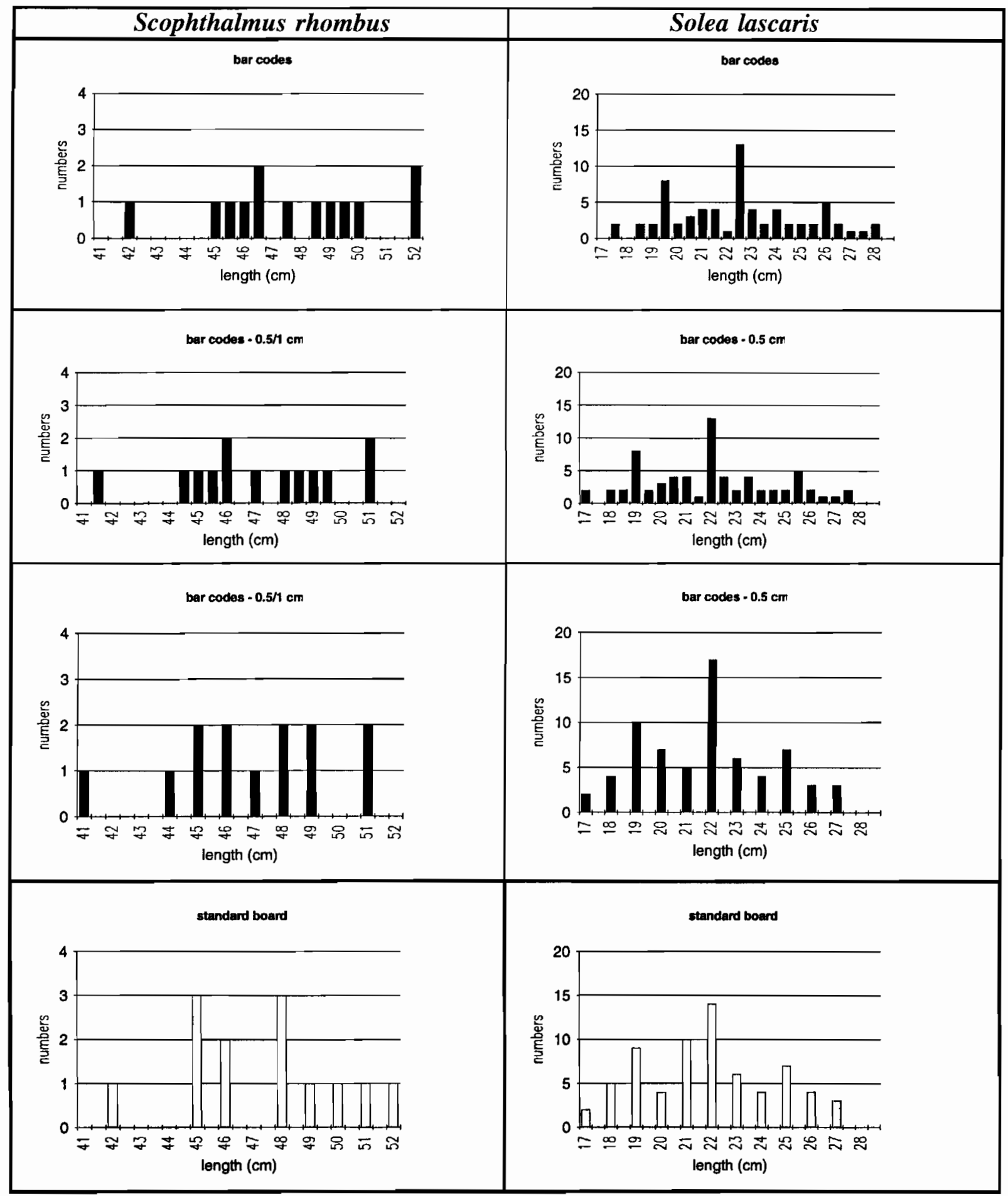

Figure 3. - Comparison of size compositions issued from the new ichthyometer and from the standard board (samples of Scophthalmus rhombus and Solea lascaris): a) when recording the bar code of the higher class; b) as (a) and followed with a correction; c) as (b) with grouped classes and d) when using the standard board.

TRANSCOD is a software product installed on the PC. It processes the file which has been transferred by Comms. The data entry hexadecimal codes are automatically converted into ASCII codes. User- modifiable function tables are used for converting the descriptors.

VALID makes it possible to output the ASCII file and edit it as required by managing the corrections or 


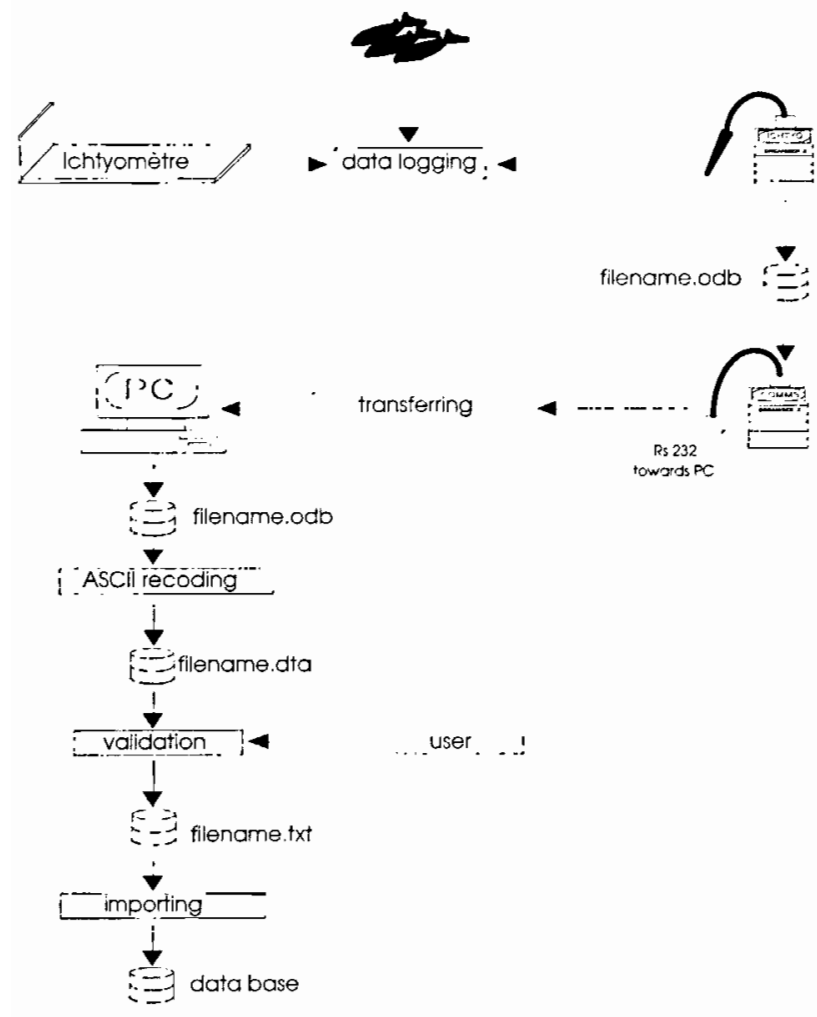

Figure 4. - Data processing when using the ichthyometer.

adding comments. The file is then ready for use by your application or for transfer to a data base.

INSERE is a software product developed in a DBase IV environment. It inserts the sampling data into a relational data base, considering the level links which govern these data. Insere has a runnable form in an MS/DOS environment and, therefore, does not require DBase to be purchased. This file format is known to many commercially available software products.

\section{CONCLUSION}

This fish measuring board is designed to meet the diverse requirements of fisheries scientists around the world for the collection of data in difficult working conditions such as encountered in the field. Such a system is open-ended. All the data required can be entered, which makes it possible to adapt to any situation. However, its capabilities must be restricted by the software to provide standardization in the data

(2) MICREL, rue Gutenberg, 56700 Hennebont, France; fax (33)97 365517. collection. The data entry software has been developed up to now on a PSION Organiser; this programmable computer has been chosen because of its pocket size, its high storage capacities, its removable memories and its transfer possibilities.

It is a system with upgrading capabilities due to the separation of board and computer. It has a watertight interface through the board and the sensor pencil.

This new fish measuring board is commercialy available ${ }^{(2)}$. It is already used by IFREMER for sampling operations both at sea and in a fish market. More than 12000 length data have recently been collected by using this system on a discards study managed at Brest. A detailed manual for users is achieved and a short video film is available in English and French version.

\section{REFERENCES}

Armstrong D. W., 1976. Development of a semi-automatic fish measuring board. ICES CM 1976/F, 37 (mimeo).

Armstrong D. W., 1981 Further development of a semiautomatic fish measuring board. ICES, CM 1981/G, 45 (mimeo).

Bayley P. B., R. F. Illyes, 1988. Measuring fish and recording data in the field and laboratory: a microcomputer application. Fisheries, 13, 15-17.

Chaput G. J., C. H. Le Blanc, C. Bourque, 1992. Evaluation of an electronic fish measuring board. ICES J. mar. Sci., 49, 335-339.

Armstrong M. C., D. A. Nagiegaal, J. A. Bartillier, 1989. Microcomputer-based measuring device for collecting biological data. Prog. Fish Cult., 51, 47-51.

Armstrong D. W., A. W. Newton, S. Jewell, 1986. A semiautomatic fish measuring board. J. Cons. int. Explor. Mer, 43, 91-94.

Grainger R. J. R., S. McLoughlin, 1986. A portable computerised system for logging of fish sample data. ICES CM 1986/G, 59.

McAllister D. E., R. J. Plank, 1981. Capturing fish measurements and counts with calipers and probe interfaced with a computer or pocket calculator. Can. J. Fish Aquat. Sci., 38, 466-470.

Morizur Y., A. Ogor, P. Lespagnol, 1991. Procédé et dispositif de mesure d'une longueur par codes à barres, et leur application au traitement du poisson. Brevet d'invention INIP $\mathrm{n}^{\circ} 9110113$.

Morizur Y., P. Lespagnol, A. Ogor, 1992. Les codes à barres dans la recherche halieutique : développement d'un ichtyomètre automatique, ICES, CM 1992/D, 6.

Newton A. W., 1984. A semi-automatic measuring board (for recording fish lengths), Scott. Fish. Bull., 48, 54-55.

Rubec P. J., R. J. Plank, 1984. The development of a portable fish measuring station for electronic data acquisition in the field. NAFO SCR Doc. 84/V1/89, 1-11.

Rubec P. J., R. J. Planck, S. N. Messieh, 1985. New developments in computerized field data acquisition equipment for grandfish surveys. NAFO SCR Doc. $85 / 104,1-13$. 